\title{
Adsorption of Thorium(IV) on Chemically Modified Amazon Clays
}

\author{
Denis L. Guerra, ${ }^{*, a}$ Rúbia R. Viana ${ }^{a}$ and Claudio Airoldi ${ }^{b}$ \\ ${ }^{a}$ Centro de Recursos Minerais, Universidade Federal de Mato Grosso, 78060-900 Cuiabá-MT, Brazil \\ ${ }^{b}$ Instituto de Química, Universidade Estadual de Campinas, CP 6154, 13084-971 Campinas-SP, Brazil
}

\begin{abstract}
Amostras de caulinita e esmectita oriundas da região Amazônica, Brasil, foram modificadas com 2-mercaptobenzimidazol (MBI) usando rotas homogênea e heterogênea. As amostras de argilas modificadas $\left(\mathrm{K}_{\mathrm{HOM}}, \mathrm{S}_{\mathrm{HOM}}, \mathrm{K}_{\mathrm{HET}}\right.$ e $\left.\mathrm{S}_{\mathrm{HET}}\right)$ foram caracterizadas por análise textural, MEV e espectroscopia ${ }^{13} \mathrm{C}$ NMR. As argilas modificadas quimicamente apresentaram modificações em suas propriedades físico-químicas incluindo: área específica 48,0 (S) para 869,8 $\mathrm{m}^{2} \mathrm{~g}^{-1}\left(\mathrm{~S}_{\mathrm{HET}}\right)$. A habilidade destes materiais para remover tório(IV) em soluções aquosas foi investigada por um série de isotermas de adsorção ajustadas pela equação de Sips em temperatura ambiente e pH 2,0. O número máximo de mols adsorvidos foi determinado em 8,29, 8,86, 9,57 e 9,89 10-1 $\mathrm{mmol} \mathrm{g}^{-1}$ para $\mathrm{K}_{\text {ном }}, \mathrm{K}_{\mathrm{HET}}, \mathrm{S}_{\mathrm{HOM}}$ e $\mathrm{S}_{\mathrm{HET}}$, respectivamente. Os efeitos energéticos causados pela adsorção do cation tório(IV) foram determinados através de metodologia calorimétrica.
\end{abstract}

Kaolinite and smectite clay samples from the Amazon region, Brazil, were modified with 2-mercaptobenzimidazole (MBI) using homogeneous and heterogeneous routes. The modified clay samples $\left(\mathrm{K}_{\mathrm{HOM}}, \mathrm{S}_{\mathrm{HOM}}, \mathrm{K}_{\mathrm{HET}}\right.$ and $\left.\mathrm{S}_{\mathrm{HET}}\right)$ were characterized by textural analysis, SEM and ${ }^{13} \mathrm{C} \mathrm{NMR}$ spectroscopy. The chemically modified clay samples showed modifications of their physicalchemical properties including: specific area $48.0(\mathrm{~S})$ to $869.8 \mathrm{~m}^{2} \mathrm{~g}^{-1}\left(\mathrm{~S}_{\mathrm{HET}}\right)$. The ability of these materials to remove thorium(IV) from aqueous solution was followed by a series of adsorption isotherms adjusted to a Sips equation at room temperature, and $\mathrm{pH}$ 2.0. The maximum number of moles adsorbed was determined to be $8.29,8.86,9.57$ and $9.8910^{-1} \mathrm{mmol} \mathrm{g}^{-1}$ for $\mathrm{K}_{\mathrm{HOM}}, \mathrm{K}_{\mathrm{HET}}$, $\mathrm{S}_{\mathrm{Hом}}$ and $\mathrm{S}_{\mathrm{HET}}$, respectively. The energetic effects $\left(\Delta_{\text {int }} \mathrm{H}, \Delta_{\text {int }} \mathrm{G}\right.$ and $\left.\Delta_{\text {int }} \mathrm{S}\right)$ caused by thorium(IV) cation adsorption were determined through calorimetry.

Keywords: kaolinite, smectite, thorium, adsorption, thermodynamic

\section{Introduction}

The chemical surface and structural properties of modified clays determine and limit their potential applications, which fall mainly into two principal categories: catalytic or adsorption processes. Presently, they can be used in a wide range of catalytic reactions, such as cracking, cyclohexane conversion, methanol alkylation of toluene, propylene oligomerization etc. They are commonly employed in the petroleum industry for long-chain hydrocarbons filtering and azeotropic cracking. ${ }^{1-3}$

Some undesirable heavy metals can be removed from aqueous solutions through chemical precipitation, ion exchange, electrodeposition, solvent extraction, membrane separation, reverse osmosis and adsorption processes. For this last procedure, the development of low cost

\footnotetext{
*e-mail: dlguerra@iqm.unicamp.br
}

adsorbents with easy manipulation and regeneration for possible reuse has been an object of significant attention, mainly when effluents are involved. ${ }^{4,5}$ Various conventional and non-conventional adsorbents have been explored for removal of different metal ions from aqueous solutions. ${ }^{6,7}$ The presence of heavy metals in the environment is of serious concern as the number of ecological and health problems associated with them is very high. Consequently, great attention has been paid in recent years to determine and remove these contaminants from aqueous systems. Natural and synthetic clay minerals have been tried for the uptake of radionuclides. Uranyl has been shown to be strongly adsorbed onto many soil constituents including clay minerals and metal oxides under appropriate chemical conditions, and therefore such materials can be used for $\mathrm{U}(\mathrm{VI})$ and $\mathrm{Th}(\mathrm{IV})$ remediation of aqueous solutons. . $^{4-9}$

Research concerning the application of the minerals to the removal of radionuclides from different aqueous 
waste systems has not been much reported. A few studies are available, that only explain the sorption characteristics of heavy metals on synthetic and natural phyllosilicates. Sheng et al. ${ }^{8}$ tested the ability of natural diatomite to remove $\mathrm{Th}(\mathrm{IV})$ from aqueous solution as a function of effects of contact time, $\mathrm{pH}$, ionic strength and temperature. The results indicated that adsorption of Th(IV) on the clay mineral and oxides is mainly dominated by surface complexation and precipitation, especially at high $\mathrm{pH}$ values. Sharma et al. ${ }^{10}$ studied the adsorption behaviour of $\mathrm{UO}_{2}^{2+}, \mathrm{Th}^{4+}$ and $\mathrm{Ru}^{3+}$ on synthetic and analogue muscovite. Depending on the synthesis procedures in some cases the extra framework aluminum species stay in the mordenite channels and restricted accessibility. The removal of uranium(VI) from aqueous solution by adsorption onto manganese oxide coated zeolite in a single component system with various contact times, $\mathrm{pH}$, competitive ions, temperatures and initial concentrations of $\mathrm{U}(\mathrm{VI})$ was investigated by Han et al. ${ }^{11}$ The ion exchange selectivity and structural changes in highly aluminous zeolites was studied by Kuronen et al. ${ }^{12}$

The aim of the present investigation was to study the performance of kaolinite and smectite phyllosilicates, obtained from the Amazon region, in natural and chemically modified forms. The chemical modification process was developed with intercalation of 2-mercaptobenzimidazole (MBI). After chemical modification, the resulting materials were used for thorium(IV) cation adsorption from aqueous solutions. The adsorption of Th(IV) on matrices was studied as a function of Th(IV) concentration ( $\mathrm{pH} 2.0$ and $298 \pm 1 \mathrm{~K}$ ). The energetic effect caused by Th(IV)/phyllosilicate surface interactions at the solid/liquid interface was determined through a calorimetric titration procedure.

\section{Experimental}

\section{Chemicals and raw materials}

2-Mercaptobenzimidazole, MBI (Aldrich) and 3-chloropropyltrimethoxysilane, CTS (Aldrich) were used without purification.

The phyllosilicates were sampled in the Amazon region, in northern Brazil. Size fractions of less than $2 \mu \mathrm{m}$ were separated by sedimentation. The cation-exchange capacity (CEC) was measured in order to evaluate the potential use of minerals for intercalation, following the ammonium acetate method with concentrations of $2.0 \mathrm{~mol} \mathrm{dm}^{-3}$ at $\mathrm{pH}$ 8.0. The results obtained were 80.0 and 25.0 meq per $100 \mathrm{~g}$ of clay, for smectite (S) and kaolinite (K), respectively on an air-dried basis. Clay samples with particle sizes of 70-230 mesh were activated in a stream of dry nitrogen by heating at $423 \pm 1 \mathrm{~K}$ for $12 \mathrm{~h}$ and used immediately.
Chemical characterization was also carried out, using analytical techniques that will be described below.

\section{Homogeneous route}

A sample of approximately of $35 \mathrm{~g}(175.0 \mathrm{mmol})$ of the silylant agent CTS was reacted with $5.50 \mathrm{~g}(34.0 \mathrm{mmol})$ of MBI compound in the presence of $8.70 \mathrm{~g}(85.0 \mathrm{mmol})$ of triethyleneamine, which was used as a deprotonating agent in order to increase the efficiency of the reaction, dissolved in $40.0 \mathrm{~cm}^{3}$ of dimethyl formamide. ${ }^{13}$ The mixture was mechanically stirred for $24 \mathrm{~h}$ at $423 \pm 1 \mathrm{~K}$. The formed product, named MBICTS, was placed in suspension with approximately $36 \mathrm{~g}$ of each natural clay sample and $50.0 \mathrm{~cm}^{3}$ of dimethyl formamide. These suspensions were mechanically stirred at reflux for $72 \mathrm{~h}$ at $423 \pm 1 \mathrm{~K}$. The resulting products were filtered, washed with deionised water, and named $\mathrm{K}_{\text {ном }}$ and $\mathrm{S}_{\text {ном }}$ (Scheme 1). ${ }^{13}$

\section{Heterogeneous route}

A sample of approximately of $35.0 \mathrm{~g}$ of each natural clay sample was suspended in $100.0 \mathrm{~cm}^{3}$ of dry xylene and $45.5 \mathrm{~g}$ (220.0 mmol) of 3-choropropyltrimethoxysilane (CTS) was added to this suspension. The mixture was reacted for $72 \mathrm{~h}$ in a reflux system at $410 \pm 1 \mathrm{~K}$. The suspensions were filtered and washed, and the products were named $\mathrm{K}_{\mathrm{CL}}$ and $\mathrm{S}_{\mathrm{CL}}$.

A sample of $34.5 \mathrm{~g}$ of $\mathrm{K}_{\mathrm{CL}}$ or $\mathrm{S}_{\mathrm{CL}}$ was reacted with $10.0 \mathrm{~g}$ $(66.0 \mathrm{mmol})$ of compound MBI and $15.6 \mathrm{~g}(154.0 \mathrm{mmol})$ of deprotonating agent (triethylamine) in $100.0 \mathrm{~cm}^{3}$ of dimethyl formamide. The suspensions were kept under reflux and mechanically stirred for $72 \mathrm{~h}$ at $423 \pm 1 \mathrm{~K}$. The final products were filtered and washed with ethanol and water and named $\mathrm{K}_{\mathrm{HET}}$ and $\mathrm{S}_{\mathrm{HET}}$ (Scheme 1). ${ }^{13}$

\section{Characterization of clay samples}

The natural samples, $\mathrm{K}$ and $\mathrm{S}$, were analyzed by inductively coupled plasma optical emission spectrometry (ICP OES), using a Perkin Elmer 3000 DV instrument. The oven-dried powdered samples weighing 230.0 and $231.0 \mathrm{mg}$, respectively, were placed separately on weighed glass dishes and transferred quantitatively to pre-cleaned nitric acid digestion bottles. The samples were then digested with $7.0 \mathrm{~cm}^{3}$ of concentrated nitric and hydrochloric acids in $1: 3$ proportions in volume, with an identical volume of hydrofluoric acid over 5 days. The samples were cooled in

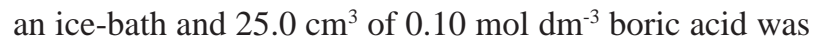
added with stirring, followed by $50.0 \mathrm{~cm}^{3}$ of deionised water, and the solution was then diluted to $100.0 \mathrm{~cm}^{3}$. 


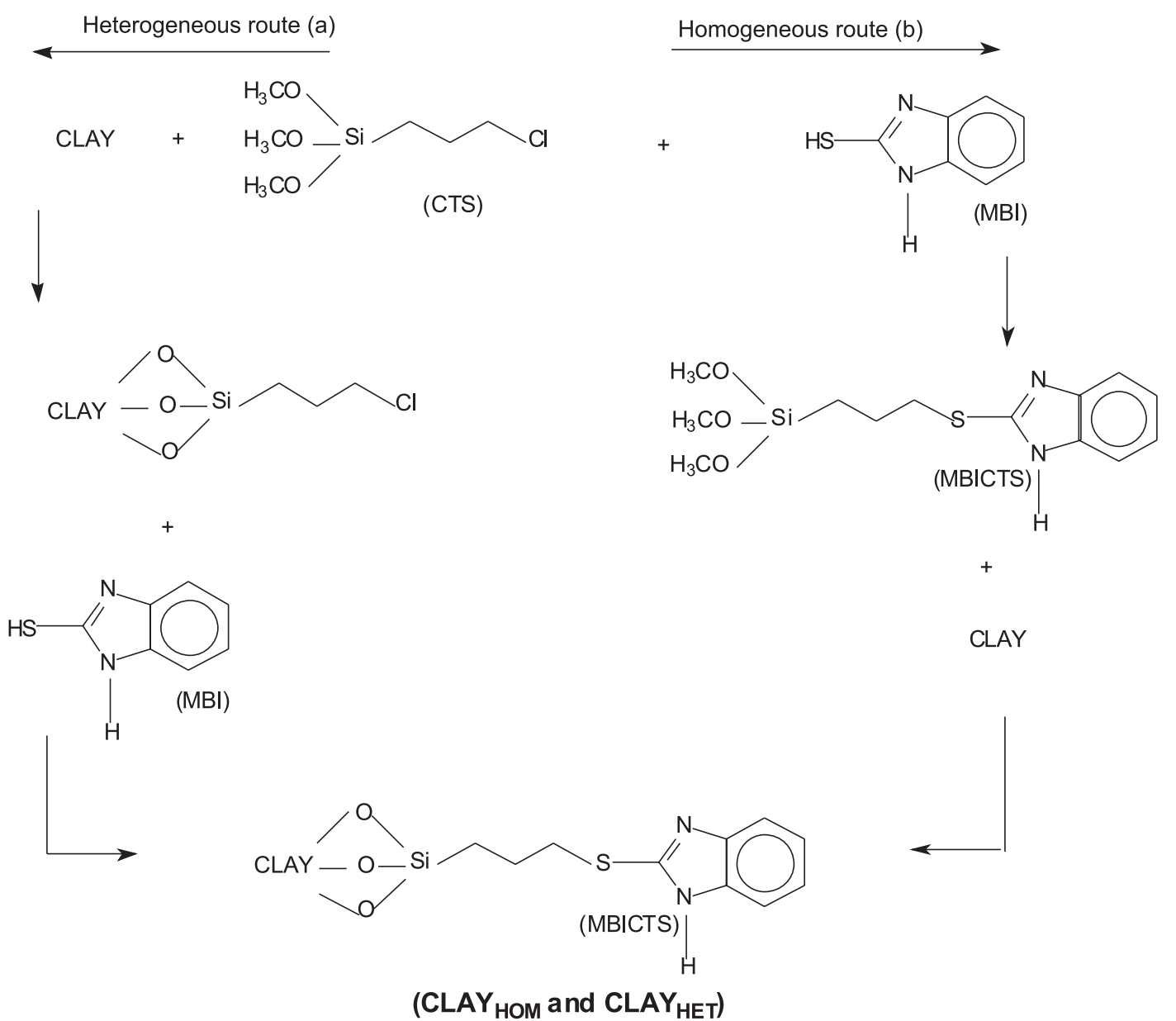

Scheme 1. Incorporation of MBI onto natural clay surfaces by heterogeneous (a) and homogeneous (b) processes.

For each sample, a blank and a set of elemental standards were run to calibrate the instruments.

BET (Brunauer-Emmett-Teller) surface areas and porosity measurements of the natural and modified mineral samples were determined using a Quantachome/Nova Surface Area-Pore Volume Analyzer, model 1200/5.01, The mesopore size distribution was obtained by applying the BJH (Barret-Joyner-Halenda) method to the adsorption branch of $\mathrm{CO}_{2}$ isotherms at $77 \pm 1 \mathrm{~K}$.

Nuclear magnetic resonance spectra of the samples were obtained on a Brucker AC 300/P spectrometer at room temperature. For each run, approximately one gram of each solid sample was compacted into a $7 \mathrm{~mm}$ zirconium oxide rotor. The measurements were obtained at frequencies of $75.47 \mathrm{MHz}$, with a magic angle spinning of $4 \mathrm{kHz}$. In order to increase the signal to noise ratio of the solid-state spectra, the CP/MAS technique was used. ${ }^{13} \mathrm{C} \mathrm{CP} / \mathrm{MAS}$ spectra were obtained with pulse repetitions of $3 \mathrm{~s}$ and a contact time of $3 \mathrm{~ms}$.

The samples for scanning electron microscopy (SEM) images were recorded on orientated blades at $298 \pm 1 \mathrm{~K}$ and sputtered with gold. The instrument used was a model LEO-ZEISS, $430 \mathrm{Vp}$, using conditions of analysis for secondary images obtained at $20 \mathrm{kV}$, with a working distance of $11 \mathrm{~mm}$.

Elemental analysis $(\% \mathrm{C}, \% \mathrm{~N}, \% \mathrm{H})$ was determined on a Perkin-Elmer 2400 Series II microelemental analyzer, and at least two independent determinations were performed for each modified clay sample.

The X-ray diffraction patterns for the natural and modified clay samples were obtained on a Shimadzu model XD3A diffractometer $(40 \mathrm{kV}, 30 \mathrm{~mA})$, in the range of $2 \theta=2.0^{\circ}-60.0^{\circ}$ with nickel-filtered $\mathrm{CuK} \alpha$ radiation, with wavelength of $1.54 \AA$. From these data the interlayer spacing of the compounds was calculated.

\section{Adsorption experiments}

The adsorption experiments were performed through the batchwise method by suspending a series of $20.0 \mathrm{mg}$ samples of the solid in $20.0 \mathrm{~cm}^{3}$ aqueous solutions of tetravalent cations at concentrations varying from 1.20 
to $2.0 \times 10^{-5} \mathrm{~mol} \mathrm{dm}^{-3}$, under orbital stirring for $24 \mathrm{~h}$ at $298 \pm 1 \mathrm{~K}$. The solid was separated by centrifugation (9000 rpm for $30 \mathrm{~min}$ ) and from the supernatant were carefully pipetted samples for cation determination. The amount of the metallic cation removed during adsorption $\left(\mathrm{mmol} \mathrm{dm}^{-3}\right)$ was calculated by the expression $\mathrm{N}_{\mathrm{f}}=\left(\mathrm{N}_{\mathrm{i}}-\mathrm{N}_{\mathrm{S}}\right) / \mathrm{m}$, were $\mathrm{N}_{\mathrm{f}}$ is the number of moles of metal adsorbed on the pendant reactive groups of the clay samples, $\mathrm{N}_{\mathrm{i}}$ and $\mathrm{N}_{\mathrm{S}}$ are the number of moles in the initial solution and in the supernatant after equilibrium, and $\mathrm{m}$ is the mass of samples used for each clay sample. ${ }^{14,15}$

Profiles of the adsorption isotherms obtained, represented by the number of moles adsorbed $\left(\mathrm{N}_{\mathrm{f}}\right)$, versus the number of moles at equilibrium per volume of solution $\left(\mathrm{C}_{\mathrm{S}}\right)$, for a series of isotherms, reveal that the adsorption process conforms to the Sips model. Sips (1948) combined the Langmuir and Freundlich equations (equation 1). The Sips isotherm is a three parameter fitting equation and combines the features of both the Freundlich and the Langmuir models. It will give a Langmuir isotherm model when $n$ is equal to $1:{ }^{16}$

$$
\mathrm{N}_{\mathrm{f}}=\frac{\mathrm{N}_{\mathrm{S}} \mathrm{K}_{\mathrm{S}} \mathrm{C}_{\mathrm{S}^{\frac{1}{n}}}}{1+\mathrm{K}_{\mathrm{S}} \mathrm{C}_{\mathrm{S}^{\frac{1}{n}}}^{\frac{1}{n}}}
$$

where $\mathrm{C}_{\mathrm{s}}$ is the concentration of the solution at equilibrium $\left(\mathrm{mol} \mathrm{dm}{ }^{-3}\right), \mathrm{N}_{\mathrm{f}}$ and $\mathrm{N}_{\mathrm{S}}$ are concentration of thorium adsorbed and the maximum amount of thorium adsorbed per gram of material $\left(\mathrm{mol} \mathrm{g}^{-1}\right)$, respectively, which depend on the number of available reactive adsorption sites, $\mathrm{K}_{\mathrm{S}}$ is the equilibrium constant and $\mathrm{n}$ is the Freundlich exponent. ${ }^{16,17}$ The percentage removal of tetravalent metal, $R_{e}$, was obtained by calculation using the equation: $\mathrm{R}_{\mathrm{e}}(\%)=\left(\mathrm{N}_{\mathrm{S}}-\mathrm{N}_{\mathrm{f}} / \mathrm{N}_{\mathrm{S}}\right) \times 100$.

The concentration of $\mathrm{Th}^{4+}$ was determined by the spectrophotometric method based on colored complexes. ${ }^{5,8}$ The concentration of thorium in the supernatant was determined with a Systronic-17 UV-Vis spectrophotometer, by measuring absorbance at a $\lambda_{\max }$ of $660 \mathrm{~nm}$ by using a Th-arsenazoIII complex. Firstly, the effect of $\mathrm{pH}$ on adsorption for all clay samples was adjusted by addition of $0.10 \mathrm{~mol} \mathrm{dm}^{-3}$ of nitric acid or $0.10 \mathrm{~mol} \mathrm{dm}^{-3}$ of sodium hydroxide. The $\mathrm{pH}$ of the solutions was measured using a pH/Ion Analyzer, model $450 \mathrm{M}$.

\section{Thermodynamic experiments}

The thermal effects from thorium cation interacting on natural and modified kaolinite and smectite samples were followed in an isothermal LKB 2277 microcalorimetric system. Portions of approximated $10 \mathrm{mg}$ of natural or modified clay samples were used for calorimetric titration. After calorimetric baseline stabilization, $20.0 \mathrm{~cm}^{3}$ of thorium cations from a $\mathrm{Th}\left(\mathrm{NO}_{3}\right)_{4} 5 \mathrm{H}_{2} \mathrm{O}$ (Aldrich) solution having a concentration of $0.050 \mathrm{~mol} \mathrm{dm}^{-3}$, were individually added to the vessel by means of a microsyringe coupled to a gold cannula. In each individual titration, the thermal effect caused by the reaction was recorded after each addition of the titrand.

\section{Non-linear method}

The coefficient of determination values $\left(\mathrm{r}^{2}\right)$ were used in order to find the degrees of fit of the isotherm adsorption and thermodynamic models with the experimental data, ${ }^{18}$ as defined by equation 2 :

$$
\mathrm{r}^{2}=\frac{\Sigma\left(\mathrm{N}_{\mathrm{fCAL}}-\overline{\mathrm{N}}_{\mathrm{fEXP}}\right)^{2}}{\Sigma\left(\mathrm{N}_{\mathrm{fCAL}}-\overline{\mathrm{N}}_{\mathrm{fEXP}}\right)^{2}+\Sigma\left(\mathrm{N}_{\mathrm{fCAL}}-\mathrm{N}_{\mathrm{fEXP}}\right)^{2}}
$$

where $\mathrm{N}_{\mathrm{fEXP}}\left(\mathrm{mmol} \mathrm{g}^{-1}\right)$ is the experimental amount of thorium cations exchanged by the unmodified and the modified phyllosilicate samples and $\mathrm{N}_{\mathrm{fCAL}}$ is the amount of cations obtained from the isotherm model.

\section{Results and Discussion}

\section{Characterization of clay samples}

Elemental analysis from the ICP OES technique for the original clay samples, $\mathrm{K}$ and $\mathrm{S}$, gave results consistent with kaolinite and smectite, with aluminum being the major component in the both clay samples. The total mineralogical compositions for kaolinite and smectite samples are given by $56.46 ; 31.42 ; 0.56 ; 0.30 ; 0.28$ and $0.20 \%$ of $\mathrm{SiO}_{2}, \mathrm{Al}_{2} \mathrm{O}_{3}$, $\mathrm{Fe}_{2} \mathrm{O}_{3}, \mathrm{Na}_{2} \mathrm{O}, \mathrm{CaO}$ and $\mathrm{K}_{2} \mathrm{O}$ and 55.30; 32.08; 1.5; 0.76; $0.31 ; 0.19$ and $0.15 \%$ of $\mathrm{SiO}_{2}, \mathrm{Al}_{2} \mathrm{O}_{3}, \mathrm{Fe}_{2} \mathrm{O}_{3}, \mathrm{MgO}, \mathrm{Na}_{2} \mathrm{O}$, $\mathrm{CaO}$ and $\mathrm{K}_{2} \mathrm{O}$, respectively, and $10.78 \%(\mathrm{~K})$ and $9.71 \%(\mathrm{~S})$ of mass was lost in the ignition process.

Nuclear magnetic resonance in the solid-state is a technique to give valuable information about the bonding of the pendant chains anchored on an inorganic backbone. For this purpose, a carbon nucleus was examined in order to better characterize the synthetic compound. Through the distribution of groups containing carbon atoms on the surface it is possible to understand the structure of the inorganic framework of the matrices and the intercalated species. Clear evidence of alkoxysilane reaction with the available groups of the intercalated clay samples is illustrated for $\mathrm{K}_{\mathrm{CL}}, \mathrm{K}_{\text {ном}}$, $\mathrm{S}_{\mathrm{HOM}}, \mathrm{S}_{\mathrm{CL}}, \mathrm{K}_{\mathrm{HET}}$ and $\mathrm{S}_{\mathrm{HET}}$ by the ${ }^{13} \mathrm{C}-\mathrm{CPMAS}-\mathrm{NMR}$ spectra, in Figures 1 and 2, respectively. In the $\mathrm{K}_{\text {ном }}, \mathrm{S}_{\text {Ном }}, \mathrm{K}_{\mathrm{HET}}$ and $\mathrm{S}_{\mathrm{HET}}$ spectra three carbon atoms related to the ligand ring, 

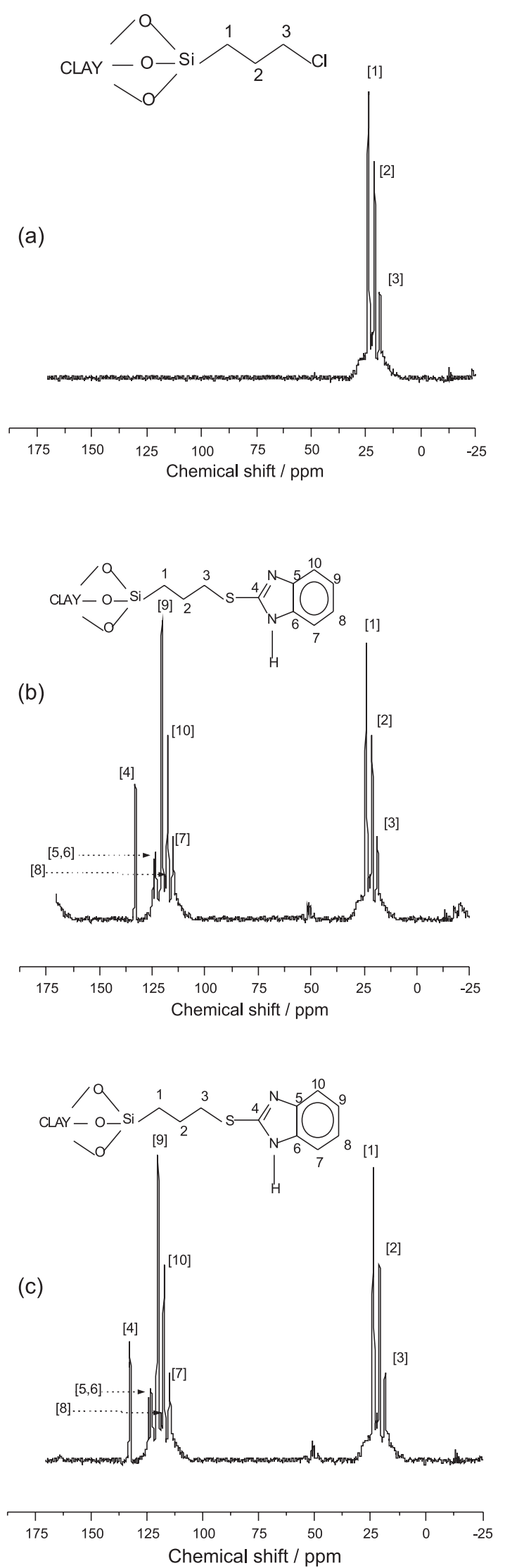

Figure 1. ${ }^{13} \mathrm{C}$ MAS NMR spectra of modified kaolinite samples: $\mathrm{K}_{\mathrm{CL}}(\mathrm{a})$, $\mathrm{K}_{\text {Hом }}(\mathrm{b})$ and $\mathrm{K}_{\mathrm{HET}}(\mathrm{c})$.

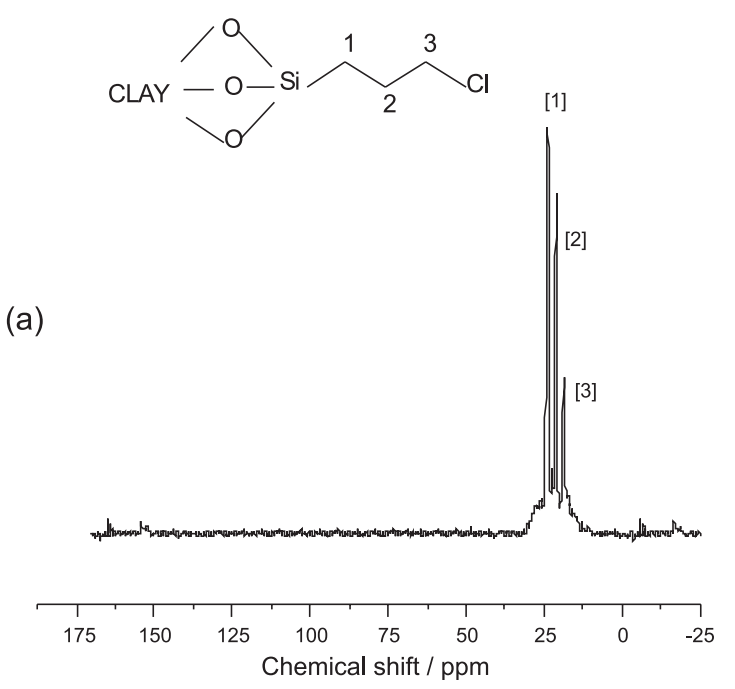

(b)
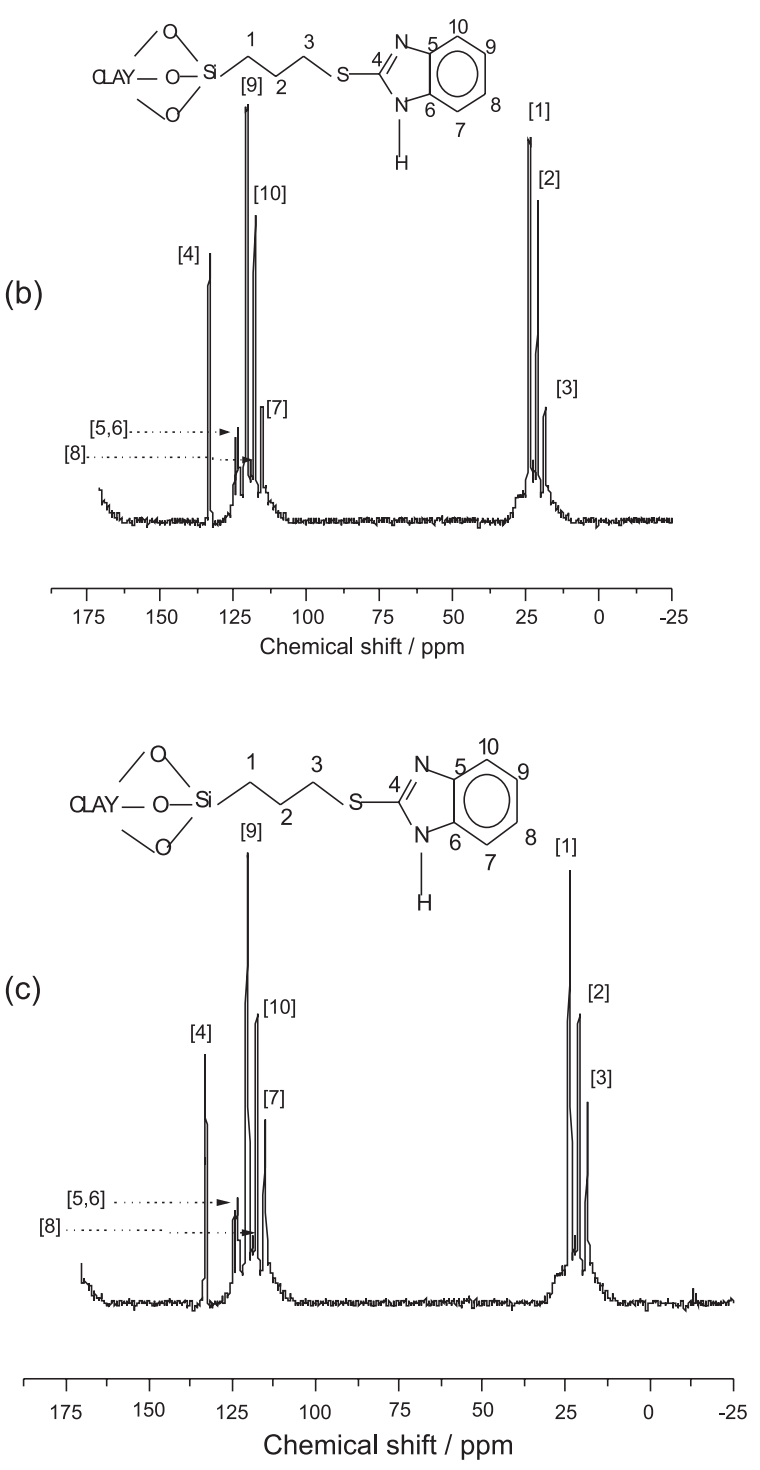

Figure 2. ${ }^{13} \mathrm{C}$ MAS NMR spectra of modified smectite samples: $\mathrm{S}_{\mathrm{CL}}$ (a), $\mathrm{S}_{\text {HOM }}$ (b) and $\mathrm{S}_{\text {HET }}$ (c). 
Table 1. Percentages of carbon $(\mathrm{C})$, hydrogen $(\mathrm{H})$ and nitrogen $(\mathrm{N})$ obtained through elemental analysis for inorganic-organic hybrids and density (d) of the pendant molecules bonded on the silicon layer

\begin{tabular}{lccr}
\hline Sample & $\mathrm{C} /(\%)$ & $\mathrm{H} /(\%)$ & $\mathrm{N} /(\%)$ \\
\hline $\mathrm{K}_{\text {HOM }}$ & $10.31 \pm 0.11$ & $1.42 \pm 0.02$ & $5.86 \pm 0.02$ \\
$\mathrm{~K}_{\text {HET }}$ & $10.81 \pm 0.23$ & $1.56 \pm 0.21$ & $5.90 \pm 0.11$ \\
$\mathrm{~S}_{\text {HOM }}$ & $12.22 \pm 0.25$ & $2.36 \pm 0.01$ & $6.3 \pm 0.21$ \\
$\mathrm{~S}_{\text {HET }}$ & $12.89 \pm 0.21$ & $2.59 \pm 0.21$ & $6.02 \pm 0.16$ \\
\hline
\end{tabular}

numbered 1, 2, and 3, give signals at 15, 19 and 23 ppm, respectively. For the $\mathrm{K}_{\text {ном }}, \mathrm{S}_{\text {ном}}, \mathrm{K}_{\mathrm{HET}}$ and $\mathrm{S}_{\mathrm{HET}}$ spectra, five well-formed peaks, at 112, 115, 119, 121 and $129 \mathrm{ppm}$, are observed. These peaks are assigned to the five carbons of pendant groups, which are numbered elements in the spectra, as the representative feature structures shown in Figures $1 \mathrm{~b}, 1 \mathrm{c}, 2 \mathrm{~b}$ and $2 \mathrm{c}$. These results provide evidence that the preparation of the new materials was successful and are in concordance with previous results. ${ }^{13}$

The successful immobilization gave the elemental analyses for the silylated surfaces as listed in Table 1. The amount incorporated was calculated based on the amount of hydrogen, nitrogen and carbon present in the modified clay samples. Based on the analytical data for the nanocompounds, the density of these pendant organic molecules immobilized on the clay layer of the phyllosilicates can be calculated. Thus, the sililant agents grafted onto clay structures gave amounts of $8.3 \pm 0.2\left(\mathrm{~K}_{\mathrm{HET}}\right)$ and $8.9 \pm 0.21 \mathrm{mmol} \mathrm{g}^{-1}\left(\mathrm{~S}_{\mathrm{HET}}\right)$.

SEM images of unmodified ( $\mathrm{S}$ and $\mathrm{K}$ ) and the chemically modified clay samples $\left(\mathrm{K}_{\mathrm{HOM}}\right.$, and $\left.\mathrm{S}_{\mathrm{HET}}\right)$ are shown in Figures 3a, 3b, 3c and 3d, respectively, presenting particles formed by large agglomerates of irregular shapes. The strong tendency toward aggregation and the compact aspect of the materials can also be observed. For the organofunctionalized clay micrographs shown in Figures $3 \mathrm{c}$ and $3 \mathrm{~d}$, the particles are apparently smaller in size and are constituted of disordered, thin sheet particle aggregates. Based on these results, it is reasonable to conclude that the functionalization
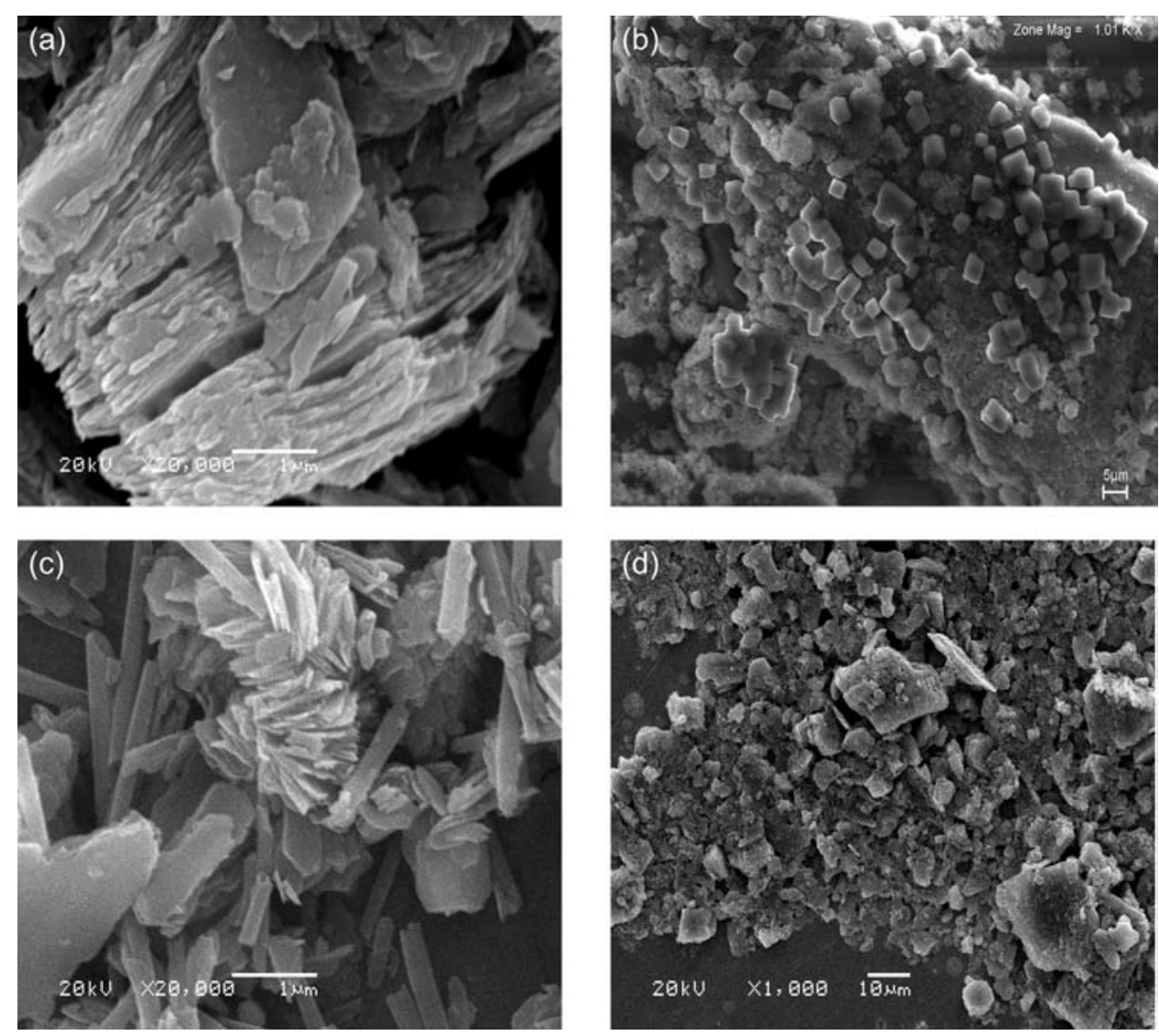

Figure 3. SEM of natural and modified clay samples: $\mathrm{K}(\mathrm{a}), \mathrm{S}(\mathrm{b}), \mathrm{K}_{\mathrm{HOM}}$ (c) and $\mathrm{S}_{\mathrm{HET}}$ (d). 
Table 2. Basal distance $\left(\mathrm{d}_{001}\right)$, surface area (S), mesopore area (M), pore volume (P) and pore diameter (DP) for unmodified and modified clays

\begin{tabular}{lccccc}
\hline Sample & $\mathrm{d}_{\text {001 }} / \mathrm{nm}$ & $\mathrm{S} /\left(\mathrm{m}^{2} \mathrm{~g}^{-1}\right)$ & $\mathrm{M} /\left(\mathrm{m}^{2} \mathrm{~g}^{-1}\right)$ & $\mathrm{P} / \mathrm{nm}$ & $\mathrm{DP} / \mathrm{nm}$ \\
\hline $\mathrm{K}$ & 0.8 & $25.3 \pm 0.11$ & $8.2 \pm 0.12$ & $3.5 \pm 0.15$ & $0.12 \pm 0.08$ \\
$\mathrm{~K}_{\text {HОм }}$ & 1.9 & $621.5 \pm 0.15$ & $110.1 \pm 0.15$ & $33.8 \pm 0.15$ & $0.71 \pm 0.04$ \\
$\mathrm{~K}_{\text {HЕT }}$ & 2.5 & $632.8 \pm 0.21$ & $112.2 \pm 0.21$ & $34.1 \pm 0.21$ & $0.72 \pm 0.21$ \\
$\mathrm{~S}$ & 1.6 & $48.0 \pm 0.17$ & $13.2 \pm 0.11$ & $5.5 \pm 0.04$ & $0.10 \pm 0.03$ \\
$\mathrm{~S}_{\text {ном }}$ & 1.9 & $869.4 \pm 0.15$ & $140.1 \pm 0.14$ & $38.8 \pm 0.11$ & $0.82 \pm 0.05$ \\
$\mathrm{~S}_{\text {НЕт }}$ & 2.6 & $869.8 \pm 0.21$ & $145.2 \pm 0.21$ & $38.9 \pm 0.21$ & $0.83 \pm 0.11$ \\
\hline
\end{tabular}

promotes the formation of disordered and less cohesive aggregates, probably due to reduction of edge-to-edge and face-to-face interactions. Unlike the hydrophilic natural clay samples, which formed large sized aggregates after drying, the functionalized samples were barely dispersed in water (hydrophobic) and easily kept as a powder after drying. This change constitutes an important advantage considering any industrial applications.

The BET surface areas of the natural and modified clay samples demonstrated that chemical modification caused the formation of micropores in the solid particles, resulting in a higher surface area, revealing $869.8 \mathrm{~m}^{2} \mathrm{~g}^{-1}$ for $\mathrm{S}_{\mathrm{HET}}$ and $632.0 \mathrm{~m}^{2} \mathrm{~g}^{-1}$ for $\mathrm{K}_{\mathrm{HET}}$, relative to the natural samples with $48.0 \mathrm{~m}^{2} \mathrm{~g}^{-1}(\mathrm{~S})$ and $25.3 \mathrm{~m}^{2} \mathrm{~g}^{-1}(\mathrm{~K})$. The pore size distribution in the mesopore region was obtained by applying the $\mathrm{BJH}$ method from $\mathrm{CO}_{2}$ isotherms at $77 \pm 1 \mathrm{~K}$. A change in pore size distribution was observed by considering natural and modified clay samples. The samples have mostly mesopores, in which natural smectite exhibited a maximum in differential pore volume, to give $5.5 \mathrm{~nm}$ in pore diameter, while for modified smectite $\left(\mathrm{S}_{\mathrm{HET}}\right)$ the pore diameter was $0.83 \mathrm{~nm}$ (See Table 2).

X-ray powder diffraction of $\mathrm{K}, \mathrm{K}_{\mathrm{HOM}}, \mathrm{K}_{\mathrm{HET}}, \mathrm{S}_{\mathrm{CL}}, \mathrm{S}_{\text {Hом }}$, and $\mathrm{S}_{\mathrm{HET}}$ showed significant changes. In Figures $4 \mathrm{a}$ and $4 \mathrm{~b}$ an increase in the interlayer distance is observed after the intercalation process, by changing $\mathrm{d}_{001}$ from 1.6 to $2.6 \mathrm{~nm}$ and 0.8 to $2.5 \mathrm{~nm}$ for $\mathrm{S}_{\mathrm{HET}}$ and $\mathrm{K}_{\mathrm{HET}}$, respectively (see Table 2). This is attributed to the presence of 2-mercaptobenzimidazol molecules that were intercalated in the clay structures, with reactive centers anchored in the interlayer spacing of the natural smectite and in the internal and external layer of natural kaolinite, such as the silanol groups. The interlayer spacing is characteristic of montmorillonite group mineral $2: 1$. The great influence of the number of organic molecules, such as MBI ions, on the interlayer spacing and on the constitution and distribution of the ions has been previously reported. ${ }^{19}$ The mass fraction of intercalation materials can be estimated as the relative intensities of the reflection originating from the 'unchanged' and the 'expanded' layer. In the intercalated samples, the degree of reaction could be estimated as $79-87 \%$ for modified smectite and $75-85 \%$ for modified kaolinite. The lesser intercalation of the kaolinite sample can be explained by the considerable stability of the kaolinite structure (1:1) that makes difficult the entrance and the anchoring of the organic molecule on the internal and external surface. In addition, this indicates that the MBI molecules arrange in the monolayer between the aluminosilicate layers.
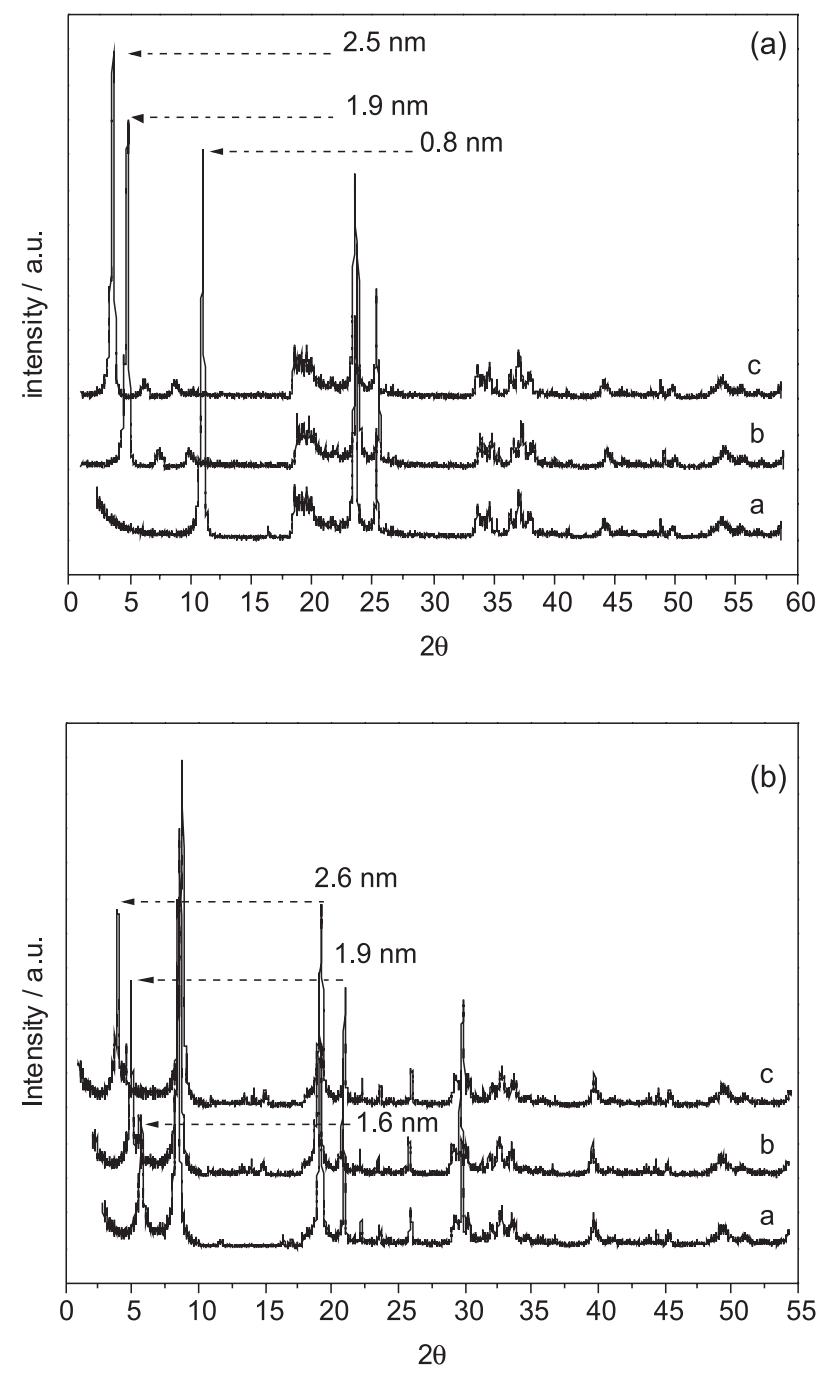

Figure 4. X-ray diffraction patterns of natural and modified clay: Kaolinite samples (A): $\mathrm{K}$ (a), $\mathrm{K}_{\mathrm{HOM}}(\mathrm{b})$ and $\mathrm{K}_{\mathrm{HET}}$ (c); Smectite samples (B): $\mathrm{S}(\mathrm{a})$, $\mathrm{S}_{\text {ном }}\left(\right.$ b) and $\mathrm{S}_{\text {HET }}$ (c). 


\section{Adsorption and thermodynamic studies}

The $\mathrm{S}, \mathrm{K}, \mathrm{S}_{\mathrm{Hом}}, \mathrm{S}_{\mathrm{HЕT}}, \mathrm{K}_{\text {ном }}$ and $\mathrm{K}_{\mathrm{HET}}$ have been used to evaluate the maximum adsorption capacity for taking up metal ions, such as $\mathrm{Th}^{4+}$, from aqueous solutions. In fact, this cation acts as on acidic Lewis center that interacts with the basic Lewis centers attached to the pendant molecules covalently bonded to the modified clay surfaces. ${ }^{19-27}$ Processes occurring at the solid/liquid interface give the isotherms that demonstrate the saturation of the natural and modified clay samples with a definite number of moles of tetravalent metallic cations, as clearly shown in Figures $5 \mathrm{a}$ and $5 \mathrm{~b}$ with the highest pronounced adsorption for $\mathrm{S}_{\mathrm{HOM}}$ and $\mathrm{S}_{\mathrm{HET}}$, respectively. Based on the ability of the pendant groups attached to the inorganic backbone in coordinating this metallic cation, the quantity can be related to $\mathrm{N}_{\mathrm{f}}$ max , which presents the values for the metal/clay
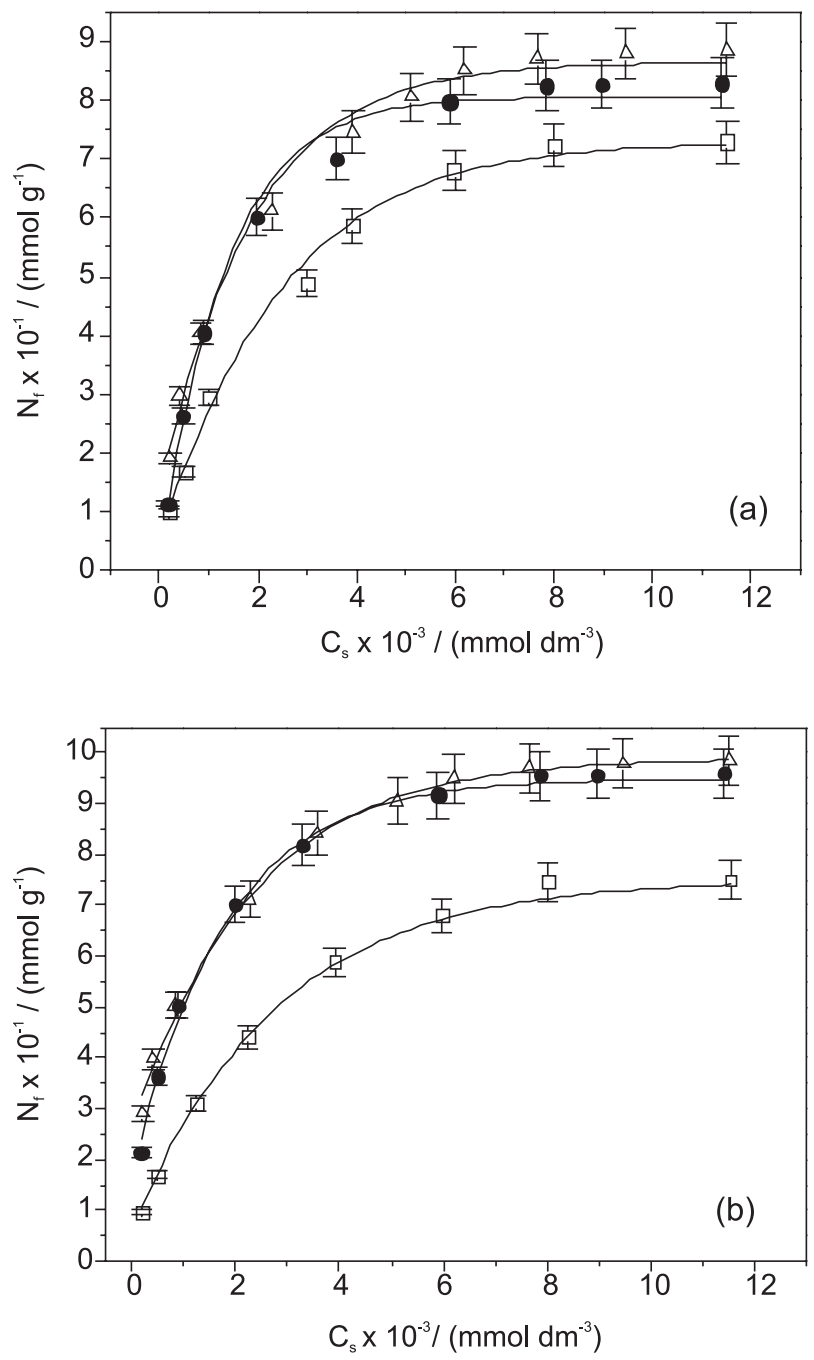

Figure 5. $\mathrm{Th}^{4+}$ cation adsorption onto natural and modified clay samples (a) $\mathrm{K} \square, \mathrm{K}_{\mathrm{HOM}} \bullet$ and $\mathrm{K}_{\mathrm{HET}} \triangle$ and (b) $\mathrm{S} \square, \mathrm{S}_{\mathrm{HOM}} \bullet$ and $\mathrm{S}_{\mathrm{HET}} \triangle$ (clay $1.0 \mathrm{~g} \mathrm{dm}^{-3}$, $\mathrm{pH} 2.0$, time $360 \mathrm{~min}$ and temperature controlled at $298 \pm 1 \mathrm{~K}$ ). system of $9.57,9.89,8.29$ and $8.86 \times 10^{-1} \mathrm{mmol} \mathrm{g}^{-1}$ for $\mathrm{S}_{\mathrm{HOM}}, \mathrm{S}_{\mathrm{HET}}, \mathrm{K}_{\text {HOM }}$ and $\mathrm{K}_{\mathrm{HET}}$, respectively (see Table 3). Some examples of different adsorbents focusing on the available radionuclide $\mathrm{Th}(\mathrm{IV})$ extraction from aqueous solutions are listed in Table 3. None of the 11 different adsorbents presented higher adsorption capacities than natural and modified clays for Th(IV) uptake, indicating that these adsorbents could be successfully employed for removal of this metallic specie from aqueous solution. ${ }^{5,8,27-33}$ As observed, the present series of results obtained from natural and modified Amazon clays present the same order of magnitude as those obtained with the magnetite, ${ }^{28}$ ferridrite ${ }^{28}$ and perlite..$^{29}$

From calorimetric titration data, the net thermal effects resulted in corresponding well-behaved isotherms that were fitted to the Sips model, as shown in Figures $6 \mathrm{a}$ and $6 \mathrm{~b}$. The complete thermodynamic data for each system studied are listed in Table 4. As observed, cation/basic center interactions for all systems are spontaneous in nature, as reflected by their negative enthalpic values. The series of exothermic enthalpic data did not permit distinguishing a preference of any particular cation to bond with the available basic centers attached to the pendant groups covalently bonded to the backbone. ${ }^{20-22}$ However, the positive entropic values for all interactions that contribute to

Table 3. Comparison of the maximum adsorption capacity ( $\mathrm{N}_{\mathrm{f}}^{\text {max }}$ ) of Th(IV) on some natural and synthetic adsorbents from aqueous solution

\begin{tabular}{|c|c|c|c|}
\hline Sample & $\begin{array}{c}\mathrm{N}_{\mathrm{f}}^{\max } / \\
\left(10^{-1} \mathrm{mmol} \mathrm{g}^{-1}\right)\end{array}$ & $\begin{array}{l}\mathrm{R}_{\mathrm{e}} / \\
(\%)\end{array}$ & Reference \\
\hline Diatomite & - & 100 & Sheng et al. ${ }^{8}$ \\
\hline Analogue mesolite & - & $10-30$ & Sarma et al. ${ }^{5}$ \\
\hline Analogue heulandite & - & 87 & Sarma et al. ${ }^{5}$ \\
\hline $\begin{array}{l}\text { Fungal (Aspergillus } \\
\text { fumigato) }\end{array}$ & - & 99 & $\begin{array}{l}\text { Bhainsa and } \\
\text { D'Souza }^{27}\end{array}$ \\
\hline Magnetite & - & 99 & Rojo et al. ${ }^{28}$ \\
\hline Ferridrite & - & 99 & Rojo et al. ${ }^{28}$ \\
\hline Perlite & - & $84 \pm 4$ & Talip et al. ${ }^{29}$ \\
\hline Bentonite & 2.75 & - & Zao et al. ${ }^{30}$ \\
\hline Al-pillared Rectorite & 1.30 & - & Yu et al. ${ }^{31}$ \\
\hline $\begin{array}{l}\text { Carbon nanotube } \\
\text { (MWCNTs) }\end{array}$ & 6.46 & - & Chen et al. ${ }^{32}$ \\
\hline Alumina & 0.75 & 99 & Guo et al. ${ }^{33}$ \\
\hline $\mathrm{K}$ & $7.32 \pm 0.11$ & 71.9 & This work \\
\hline $\mathrm{K}_{\text {ном }}$ & $8.29 \pm 0.12$ & 81.5 & This work \\
\hline $\mathrm{K}_{\mathrm{HET}}$ & $8.86 \pm 0.11$ & 87.1 & This work \\
\hline S & $7.51 \pm 0.13$ & 73.8 & This work \\
\hline $\mathrm{S}_{\mathrm{HOM}}$ & $9.57 \pm 0.14$ & 94.1 & This work \\
\hline$\underline{\mathrm{S}_{\mathrm{HET}}}$ & $9.89 \pm 0.11$ & 97.2 & This work \\
\hline
\end{tabular}


Table 4. Adsorption and thermodynamic data for Th(IV) cation adsorption for unmodified and modified clays (pH 2.0, time $360 \mathrm{~min}$ at $298 \pm 1 \mathrm{~K}$ )

\begin{tabular}{|c|c|c|c|c|c|c|c|c|c|}
\hline Sample & $\mathrm{K}_{\mathrm{S}} \times 10^{-3}$ & $r^{2}$ & $\begin{array}{c}\mathrm{N}_{\mathrm{s}} / \\
\left(10^{-3} \mathrm{mmol} \mathrm{g}^{-1}\right)\end{array}$ & $\begin{array}{l}-\Delta_{\text {int }} \mathrm{h} / \\
\left(\mathrm{J} \mathrm{g}^{-1}\right)\end{array}$ & $\begin{array}{c}-\Delta_{\text {int }} \mathrm{H} / \\
\left(\mathrm{K} \mathrm{J} \mathrm{mol}^{-1}\right)\end{array}$ & $\mathrm{n}$ & $\mathrm{LnK}_{\mathrm{S}}$ & $\begin{array}{c}-\Delta_{\text {int }} \mathrm{G} / \\
\left(\mathrm{K} \mathrm{J} \mathrm{mol}^{-1}\right)\end{array}$ & $\begin{array}{c}\Delta_{\text {int }} \mathrm{S} / \\
\left(\mathrm{J} \mathrm{K}^{-1} \mathrm{~mol}^{-1}\right)\end{array}$ \\
\hline K & $8.83 \pm 0.13$ & 0.999 & $7.80 \pm 0.20$ & $56.57 \pm 0.20$ & $7.24 \pm 0.11$ & 0.78 & 9.09 & $22.5 \pm 0.1$ & $51 \pm 1$ \\
\hline $\mathrm{K}_{\text {ном }}$ & $11.05 \pm 0.12$ & 0.998 & $8.78 \pm 0.11$ & $61.63 \pm 0.20$ & $7.02 \pm 0.12$ & 0.79 & 9.31 & $23.1 \pm 0.1$ & $54 \pm 1$ \\
\hline $\mathrm{K}_{\mathrm{HET}}$ & $11.13 \pm 0.21$ & 0.998 & $9.87 \pm 0.11$ & $66.23 \pm 0.20$ & $6.71 \pm 0.11$ & 0.79 & 9.32 & $23.1 \pm 0.1$ & $55 \pm 2$ \\
\hline S & $9.71 \pm 0.11$ & 0.997 & $7.79 \pm 0.10$ & $56.24 \pm 0.20$ & $7.22 \pm 0.12$ & 0.89 & 9.18 & $22.8 \pm 0.1$ & $52 \pm 1$ \\
\hline $\mathrm{S}_{\mathrm{HOM}}$ & $12.17 \pm 0.15$ & 0.999 & $10.45 \pm 0.09$ & $68.76 \pm 0.20$ & $6.58 \pm 0.11$ & 0.90 & 9.41 & $23.3 \pm 0.1$ & $56 \pm 1$ \\
\hline$S_{\mathrm{HET}}$ & $12.23 \pm 0.21$ & 0.998 & $10.96 \pm 0.08$ & $69.23 \pm 0.20$ & $6.32 \pm 0.15$ & 0.91 & 9.41 & $23.3 \pm 0.2$ & $57 \pm 3$ \\
\hline
\end{tabular}
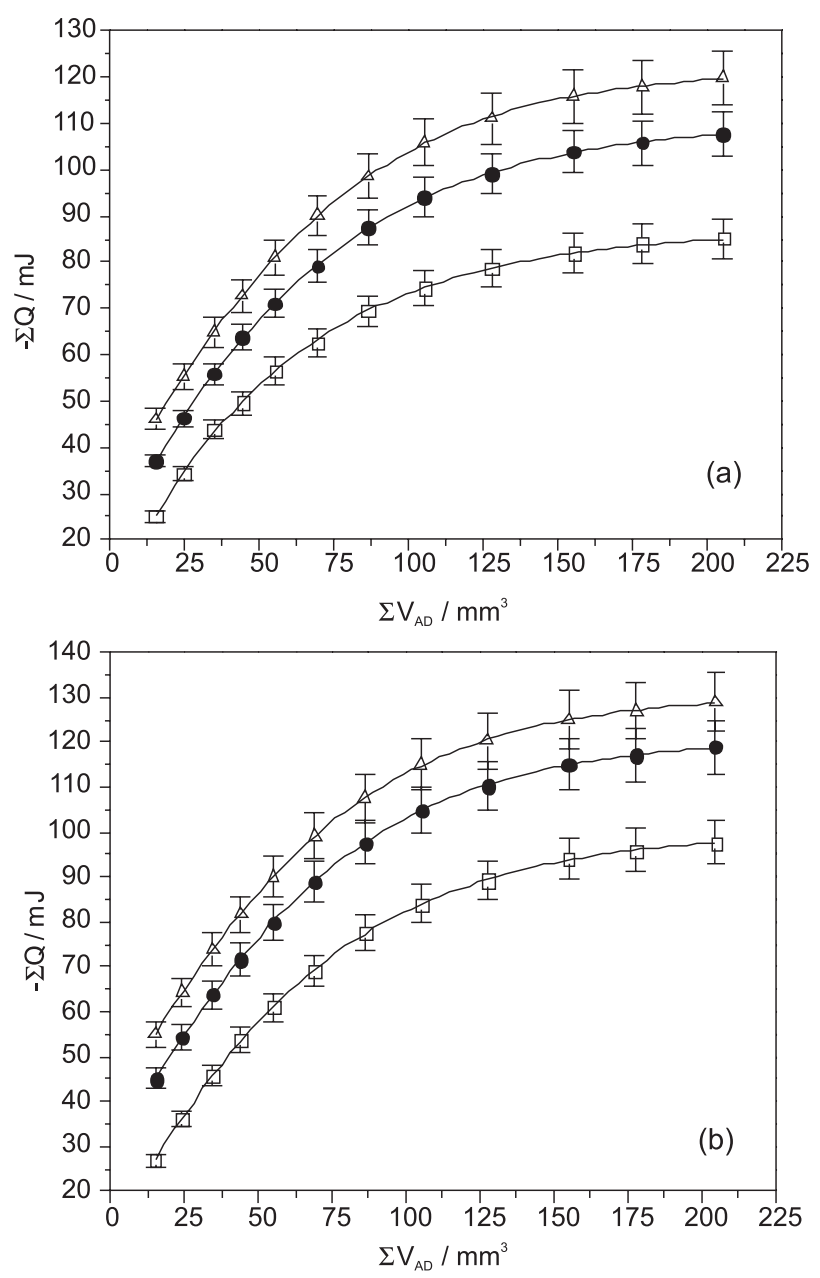

Figure 6. The resulting thermal effects of the adsorption isotherms for the $\mathrm{Th}^{4+}$ cation: (a) $\mathrm{K} \square, \mathrm{K}_{\mathrm{HOM}} \bullet$ and $\mathrm{K}_{\mathrm{HET}} \triangle$ and (b) $\mathrm{S} \square, \mathrm{S}_{\mathrm{HOM}} \bullet$ and $\mathrm{S}_{\mathrm{HET}} \triangle$ (clay $1.0 \mathrm{~g} \mathrm{dm}^{-3}, \mathrm{pH} 2.0$ ).

the favorable interactive process are associated with solvent molecule displacement, initially bonded to the modified clay samples, which is reinforced by desolvation of the metallic cations before interacting with basic centers. In such interactive processes the increase in free molecules in the reaction medium gives a positive entropy, thus demonstrating a favorable set of thermodynamic data for this kind of system. ${ }^{23-26}$
The thermodynamic cycles for this series of clay samples (CLAY) involving a heterogeneous condition considered the suspension ( $\mathrm{sp}$ ) of these matrices in aqueous (aq) solution, which are calorimetrically titrated with thorium cation, $\Sigma \Delta_{\text {tit }} \mathrm{h}$, followed by hydration of each clay sample, $\Sigma \Delta_{\text {hid }} \mathrm{h}$, and also the dilution of the cation solution, $\Sigma \Delta_{\text {dil }} \mathrm{h}$, as represented by the following reactions (equations 3-6):

$$
\begin{aligned}
& \mathrm{CLAY}_{\mathrm{sp}}+\mathrm{Th}^{4+}{ }_{\mathrm{aq}}=\mathrm{CLAY}_{\ldots} . \mathrm{Th}_{\mathrm{sp}}^{4+} \quad \Sigma \Delta_{\mathrm{tit}} \mathrm{h} \\
& \mathrm{CLAY}_{\mathrm{sp}}+\mathrm{nH}_{2} \mathrm{O}=\mathrm{CLAY}_{\mathrm{nH}} \mathrm{O}_{\mathrm{sp}} \quad \Sigma \Delta_{\text {hid }} \mathrm{h} \\
& \mathrm{Th}^{4+}{ }_{\text {aq }}+\mathrm{nH}_{2} \mathrm{O}=\mathrm{Th}^{4+} \cdot \mathrm{nH}_{2} \mathrm{O}_{\text {aq }} \quad \Sigma \Delta_{\text {dil }} \mathrm{h} \\
& \mathrm{CLAY}_{\mathrm{sp}}+\mathrm{Th}^{4+}{ }_{\mathrm{aq}}=\mathrm{CLAY} \ldots \mathrm{Th}^{4+} \quad \Sigma \Delta_{\mathrm{r}} \mathrm{h}
\end{aligned}
$$

The net thermal effect, $\Sigma \Delta_{\mathrm{r}} \mathrm{h}$, can be obtained from the expression: $\Sigma \Delta_{\mathrm{r}} \mathrm{h}=\Sigma \Delta_{\text {tit }} \mathrm{h}-\Sigma \Delta_{\text {hid }} \mathrm{h}-\Sigma \Delta_{\text {dil }} \mathrm{h}$, due to the fact that the matrix hydration values are null. During recent years many investigations in a variety of the systems concerning the solvent effect on different matrices have shown that this thermal effect is equal to zero. The corresponding isotherms shown in Figures $6 \mathrm{a}$ and $6 \mathrm{~b}$ demonstrate that natural clay samples differ from those anchored with nitrogen and sulfur basic atoms attached to the pendant chains. ${ }^{27}$

\section{Regeneration of the adsorbents}

Desorption and regeneration studies give an idea about the nature of adsorption. Desorption experiments were carried-out in order to verify the possible mechanism of adsorption of Th(IV) on original and modified clays. Batch desorption studies were carried out by agitating $20.0 \mathrm{~cm}^{3}$ of $100 \mathrm{mg} \mathrm{dm}^{-3}$ metallic ion solutions with $80.0 \mathrm{mg}$ of natural and modified clay for $350 \mathrm{~min}$. The remaining liquid phase was separated from the solid phase, and the metal-loaded adsorbents were first washed with deionised water for removing non-adsorbed metallic ions. Then, the 

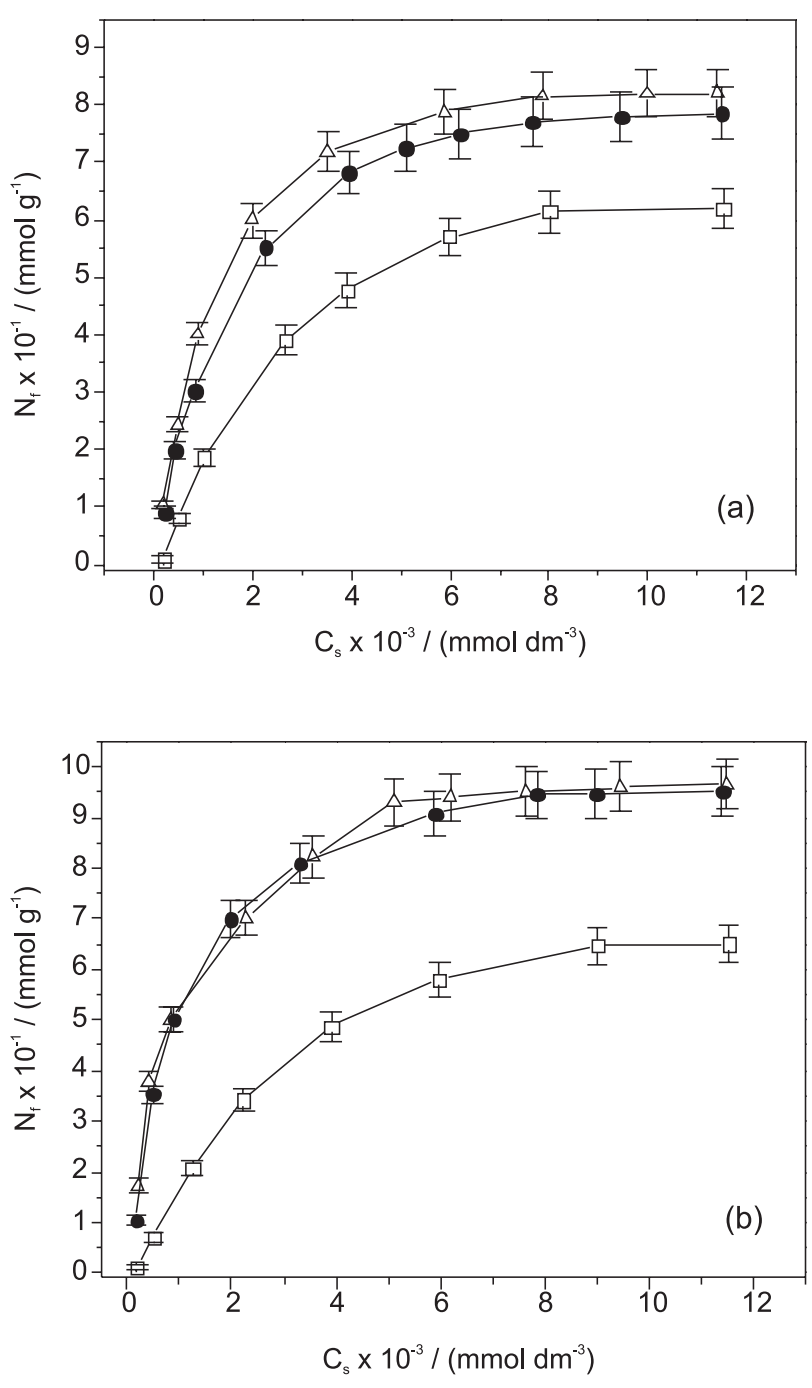

Figure 7. Divalent metal adsorption onto regenerate adsorbents: (a) K $\square$, $\mathrm{K}_{\mathrm{HOM}} \bullet$ and $\mathrm{K}_{\mathrm{HET}} \triangle$ and (b) $\mathrm{S} \square, \mathrm{S}_{\mathrm{HOM}} \bullet$ and $\mathrm{S}_{\mathrm{HET}} \triangle$ (clay $1.0 \mathrm{~g} \mathrm{dm}^{-3}, \mathrm{pH} 2.0$, time $360 \mathrm{~min}$ and temperature controlled at $298 \pm 1 \mathrm{~K}$ ).

metal-loaded adsorbents were agitated with $20.0 \mathrm{~cm}^{3}$ of aqueous solutions: $1.00 \mathrm{~mol} \mathrm{dm}^{-3}(\mathrm{HCl}), 1.00 \mathrm{~mol} \mathrm{dm}^{-3}$ $\left(\mathrm{HNO}_{3}\right)$ or $0.50 \mathrm{~mol} \mathrm{dm}^{-3}(\mathrm{NaOH})$ up to $1 \mathrm{~h}$. It was observed that $\mathrm{NaOH}$ did not promote any remarkable removal of the metallic ions from the adsorbents after $1 \mathrm{~h}$ of contact time $(<10.0 \%)$. In addition, the best recovery results were achieved by using $\mathrm{HCl}(\geq 95.0 \%)$ and $\mathrm{HNO}_{3}$ $(\geq 98.0 \%)$. These results indicate that the metallic ions should interact with the pendant groups attached to the inorganic backbone of the kaolinite and smectite. In order to verify the reutilization of the regenerated absorbents, they were again employed for metal uptake in new cycles of adsorption. It was observed that the adsorption capacities were about $82.0 \%, 86.0 \%, 92.0 \%, 86.0 \% 97.0 \%$ and $98.0 \%$ of the original absorbents, $\mathrm{K}, \mathrm{K}_{\mathrm{HOM}}, \mathrm{K}_{\mathrm{HET}}, \mathrm{S}$, $\mathrm{S}_{\mathrm{HOM}}$ and $\mathrm{S}_{\mathrm{HET}}$, respectively, for $\mathrm{Th}(\mathrm{IV}$ ) (see Figures $7 \mathrm{a}$ and $7 \mathrm{~b}$ ), indicating that original and modified Amazon clays could be good alternative adsorbents for tetravalent thorium removal from aqueous solutions.

\section{Conclusions}

The immobilization of 2-mercaptobenzimidazole molecules onto natural clay surfaces was obtained with success through both the homogeneous and heterogeneous routes, producing similar materials in all aspects. The radionuclide adsorption studies with the modified clay structures demonstrated that the inorganic-organic hybrid materials can act as chelating agents in pollutant metal ion removal from aqueous solution. The maximum adsorption showed the following order: $\mathrm{S}_{\mathrm{HET}}>\mathrm{S}_{\mathrm{HOM}}>\mathrm{K}_{\mathrm{HET}}>\mathrm{K}_{\mathrm{HOM}}>\mathrm{S}>$ $\mathrm{K}$ for all studied systems. These results are in agreement with the affinity of the reactive basic centers for cation coordination on the available pendant groups attached in the inorganic backbone. The series of thermodynamic data reflects the favorable cation/basic center interaction at the solid/liquid interface.

\section{Acknowledgments}

The authors are indebted to CNPq and FAPESP for fellowships and financial support.

\section{References}

1. Bahamonde, A.; Mohino, F.; Rebollar, M.; Yates, M.; Avila, P.; Mendioroz, S.; Catal. Today 2001, 69, 233.

2. Hutson, N. D.; Hoesksta, M. J.; Yang, R. T.; Microporous Mesoporous Mater. 1999, 28, 447.

3. Kloprogge, J. T.; Evans, R.; Hickey, L.; Frost, R.L.; Appl. Clay Sci. 2002, 20, 157.

4. Shahwan, T.; Erten, H. N.; Radiochim. Acta 2005, 93, 225.

5. Sharma, P.; Tomar, R.; Microporous Mesoporous Mater. 2008, $116,641$.

6. Nemes, Z.; Nagy, N. M.; Kónya, J.; J. Radioanal. Nucl. Chem. 2005, 266, 289.

7. Salih, B.; Denizli, A.; Kavakli, C.; Pişkin, E.; Talanta 1998, 46, 1205.

8. Sheng, G.; Hu, J.; Wang, X.; Appl. Radiat. Isot. 2008, 66, 1313.

9. Xiu-Wen, W.; Hong-Wen, M.; Jin-Hong, L.; Zhang, J.; ZhiHong, L.; J. Colloid Interface Sci. 2007, 315, 555.

10. Sharma, P.; Tomar, R.; Sharma, P.; Tomar, R.; J. Radioanal. Nucl. Chem. 2006, 268, 329.

11. Han, R.; Zou, W.; Wang, Y.; Zhu, L.; J. Environ. Radioact. 2007, 93, 127.

12. Kuronen, M.; Weller, M.; Townsend, R.; Harjula, R.; React. Funct. Polym. 2006, 66, 1350. 
13. Evangelista, S. H. M.; De Oliveira, E.; Castro, G. R.; Zara, L. F.; Prado, A. G. S.; Surf. Sci. 2007, 601, 2194.

14. Guerra, D. L.; Airoldi, C.; Lemos, V. P.; Angélica, R. S.; J. Hazard. Mater. 2008, 155, 230.

15. Guerra, D. L.; Lemos, V. P.; Airoldi, C.; Angélica, R. S.; Polyhedron 2006, 25, 2880.

16. Sips, R.; J. Chem. Phys. 1948, 16, 490.

17. Cestari, A. R.; Vieira, E. F. S.; Vieira, G. S.; da Costa, L. P.; Tavares, A. M. G.; Loh, W.; Airoldi, C.; J. Hazard. Mater. 2009, 161, 307.

18. Karadag, D.; Koc, Y.; Turan, M.; Ozturk, M.; J. Hazard. Mater. 2007, 144, 432.

19. Quintanilla, D. P.; Del Hierro, I.; Fajardo, M.; Serra, I.; J. Hazard. Mater. 2006, 134, 245.

20. Guerra, D. L.; Airoldi, C.; Viana, R. R.; Inorg. Chem. Commun. 2008, 11, 20.

21. Lazarin, A. M.; Airoldi, C.; Thermochim. Acta 2007, 454, 43.

22. Macedo, T. R.; Petrucelli, G. C.; Airoldi, C.; Clays Clay Miner. 2007, 55, 151.

23. Prado, A. G. S.; Airoldi, C.; Anal. Chim. Acta 2001, 432, 201.

24. Ruiz, V. S. O.; Airoldi, C.; Thermochim. Acta 2004, 420, 73.
25. Tang, X.; Li, Z.; Chen, Y.; J. Harzard. Mater. 2009, 161, 824.

26. Fonseca, M. G.; Simoni, J. A.; Airoldi, C.; Thermochim. Acta 2001, 369, 17.

27. Bhainsa, K. C.; D’Souza, Z. F.; J. Hazard. Mater. 2009, 165, 670.

28. Rojo, I.; Seco, F.; Rovina, M.; Giménez, J.; Cervantes, G.; Martí, V.; de Paplo, J.; J. Nucl. Mater. 2009, 385, 474.

29. Talip, Z.; Eral, M.; Hiçsönhez, Ü.; J. Environ. Radioact. 2009, $100,139$.

30. Zao, D. L.; Feng, S. J.; Chen, C. L.; Chen, S. H.; Xu, D.; Wang, X. K.; Appl. Clay Sci. 2008, 17, 41.

31. Yu, S. M.; Chen, C. L.; Chang, P. P.; Wang, T. T.; Lu, S. S.; Wang, X. K.; Appl. Clay Sci. 2008, 38, 219.

32. Chen, C.; Li, X.; Zhao, D.; Tan, X.; Wang, X.; Colloids Surf., A 2007, 302, 449.

33. Guo, Z.; Yu, X.; Guo, F.; Tao, Z.; J. Colloid Interface Sci. 2005, $288,14$.

Received: January 30, 2009

Web Release Date: June 29, 2009

FAPESP helped in meeting the publication costs of this article. 